\title{
Celiac disease - Hidden and dangerous
}

\author{
Shelley Case BSc RD ${ }^{1}$, Paul C Adams MD², Editor-in-Chief
}

S helley Case is one of North America's leading nutritional Sexperts on celiac disease (CD) and the gluten-free diet (GFD). She is a member of the Canadian Celiac Association (CCA) Professional Advisory Board and the Medical Advisory Boards of the Celiac Disease Foundation and the Gluten Intolerance Group in the United States (US). She is a popular speaker and has delivered numerous lectures and workshops at national and regional medical, dietetic, celiac and food industry conferences throughout the US and Canada, including the National Institutes of Health Consensus Development Conference on Celiac Disease. Her national bestseller, GlutenFree Diet: A Comprehensive Resource Guide, is highly recommended by health professionals, patients and celiac organizations. Shelley Case has her own nutrition consulting business in Regina, Saskatchewan.

PA: Can you discuss the prevalence of $\mathrm{CD}$ in the Canadian population.

SC: The University of Ottawa Evidence-Based Practice Center (Ottawa, Ontario) reported at the National Institutes of Health Consensus Development Conference on Celiac Disease, that the worldwide prevalence of CD is between 1:100 to 1:200 people. There are no Canadian prevalence data; however, a recent multicentre study (1) revealed a prevalence of $1: 133$ people in the US. CD occurs more frequently in certain populations, eg, among first-degree relatives of individuals with biopsy-proven CD (range $4 \%$ to $15 \%$ ), in second-degree relatives (range 3\% to $7 \%$ ), individuals with type I diabetes (range $3 \%$ to $10 \%$ ) and Down's syndrome (range $2 \%$ to $5 \%$ ), and is also associated with Turner's syndrome and selective immunoglobulin A deficiency.

PA: What are the most common presenting features of CD in Canada?

SC: It is now recognized that CD is a multisymptom, multisystem disorder with the nature and severity of symptoms varying widely, especially among adults. New data (2-4) suggest that less than $50 \%$ of newly diagnosed patients with CD present with the classic gastrointestinal symptoms of bloating, abdominal pain, diarrhea and/or constipation. In a recent Canadian celiac health survey (5) of 2681 adults with biopsyproven $\mathrm{CD}$, other symptoms that were revealed included extreme weakness or fatigue $(68 \%)$, anemia $(66 \%)$, mood swings or depression (44\%), bone or joint pain (38\%), easy bruising (35\%), nausea or vomiting (29\%), aphthous ulcers (26\%) and migraine (24\%). Other common symptoms included dental enamel defects, arthritis, delayed puberty, abnormal liver enzymes (alanine aminotransferase and aspartate aminotransferase), infertility in both men and women, neurological conditions such as unexplained ataxia or peripheral neuropathy, and epilepsy with occipital calcifications. New screening tests have markedly exposed the presentations of $\mathrm{CD}$. However, these tests are not perfect and all the guidelines still recommend intestinal biopsy as the definitive test for the diagnosis of CD.

PA: What medical complications can occur in CD without diarrhea?

SC: Untreated CD can result in nutritional deficiencies (especially iron deficiency anemia), increased risk of osteoporosis, lymphoma, reproductive complications such as miscarriage and infertility (in both men and women) and possible development of other autoimmune disorders.

PA: There is an increased risk of small intestinal cancer in CD. Does this justify a GFD in a patient without diarrhea?

SC: Regardless of the presenting symptoms, all patients with biopsy-proven CD must follow a strict GFD for life. The good news is that patients who follow a strict GFD have no greater incidence of intestinal lymphoma once they have been on the diet for five years.

PA: A gastroenterologist may order celiac serology and perform a duodenal biopsy. Follow-up arrangements after the biopsy are highly variable. Can you discuss what often happens and what would be ideal?

SC: There are no consensus guidelines in North America for the follow-up of individuals with CD; therefore, follow-up is highly variable and decisions are usually made by the gastroenterologists on a case-by-case basis. Immediate follow-up at the time of diagnosis should include testing for nutrient deficiencies, bone mineral density and other autoimmune diseases, if signs or symptoms are present. In addition, an immediate referral to a registered dietitian is essential. PA: There are many information sources on CD and the GFD, including your book and the Internet. Is this enough for most patients or do they benefit from multiple visits to a dietitian? SC: The reason why I wrote my book was to address the shortage of accurate and up-to-date information on CD and the GFD for patients, physicians and dietitians. Although the book is very comprehensive, a newly diagnosed patient also needs an individualized nutritional assessment, diet education and ongoing follow-up from a registered dietitian with 


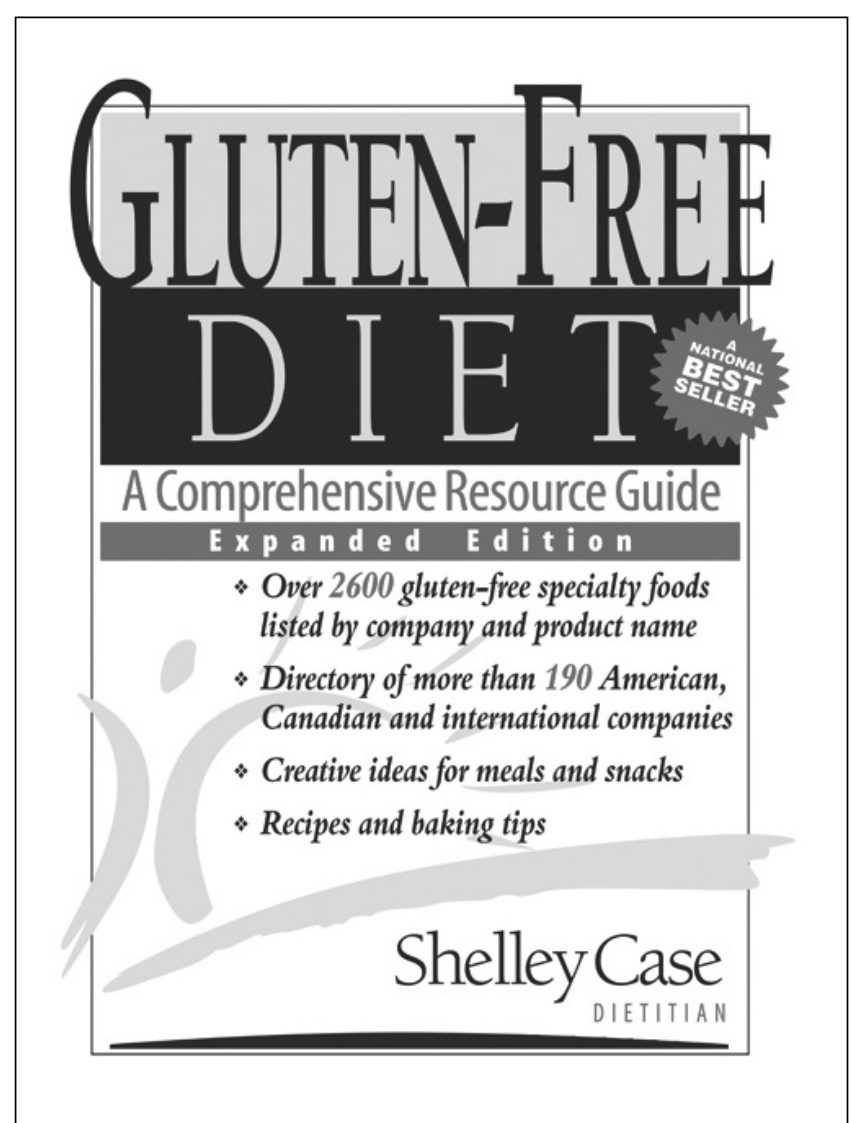

Gluten-Free Diet: A Comprehensive Resource Guide by Shelley Case (Case Nutrition Consulting 2006. ISBN 1-897010-28-1, CDN\$26.95). Web site www.glutenfreediet.ca

expertise in CD and the GFD to help them successfully adapt to this complex diet and new lifestyle. This can be very challenging for most people for several reasons - wheat and wheat-based products are major staples in the North American diet, hectic lifestyles have resulted in more meals eaten away from home and greater reliance on prepackaged foods which often contain wheat or barley, gluten is often a hidden ingredient in many foods because Canadian labelling regulations do not require manufacturers to declare all components of ingredients on the food label (eg, seasonings, modified food starch and hydrolyzed vegetable proteins), and the cost of gluten-free specialty foods such as breads, cereals, pastas, etc, is significantly higher than gluten-containing foods and obtaining these foods is often difficult for those who do not live in larger city centres.

It is also highly recommended that individuals with $\mathrm{CD}$ join the CCA to obtain educational information and ongoing support. The CCA is the only recognized national support group for individuals with $\mathrm{CD}$, with 27 local chapters across Canada (see www.celiac.ca).

PA: You are in private practice in Regina, Saskatchewan, and patients pay a fee for your service. Is this becoming common in Canada or do patients expect dietetic services to be provided free in ambulatory care settings in hospitals?

SC: Most gastroenterologists are aware of the need for referral to an experienced dietitian but there are regional variations in patient access to this important resource, often making referral to a dietitian difficult and challenging. For those patients who are referred, the majority are seen by an outpatient hospital dietitian. Some insurance companies pay for consultation with a private practice dietitian; however, many patients must pay out of their pocket for this service.

PA: Can you comment on the new development in the GFD about oats?

SC: A number of studies (6-12) in Europe and the US over the past 10 years in both children and adults with $C D$, have revealed that consumption of moderate amounts of pure, uncontaminated oats is safe for the majority of people with CD. In response to this research, the CCA Professional Advisory Board has recently issued a position statement on the use of pure, uncontaminated oats for patients with CD (see www.celiac.ca) which has been approved by Health Canada. It should be noted that commercial oat products in North America are contaminated with wheat and/or rye, and barley, and are not safe. However, there are new Canadian companies who now produce pure, uncontaminated oat products for this growing niche market.

PA: How do you predict the risk of CD in a family or from a mother to child?

SC: There is no way to definitively predict CD risk in children or siblings. Human leukocyte antigen (HLA)-DQ2 and HLA-DQ8 tests are markers of CD. Unfortunately these tests are not generally available in Canada, and $20 \%$ to $30 \%$ of the North American population are HLA-DQ2- or HLA-DQ8positive. Approximately $98 \%$ of individuals with CD are HLA-DQ2- or HLA-DQ8-positive. Thus, a negative HLADQ2 or HLA-DQ8 test in a family member where the index CD patient is HLA-DQ2- or HLA-DQ8-positive excludes the risk of $\mathrm{CD}$ in the HLA-DQ2-or HLA-DQ8-negative relative for life.

The CCA has posted a statement on breastfeeding and CD on their Web site (www.celiac.ca). Data from several studies $(13,14)$ suggest that introducing gluten in small amounts at five to six months of age, while continuing to breastfeed, decreases the risk of developing CD in early childhood. It is not known if this feeding regimen protects the child for life.

PA: Some patients have positive serology and a negative biopsy. Others have negative serology but have symptoms and/or a family history. Should they follow a GFD?

SC: With any screening test there are false-positives and falsenegatives. False-positives are most often found where there is a second autoimmune disease present, such as type I diabetes or autoimmune liver disease. In CD, this can be further complicated by the introduction of a GFD before an intestinal biopsy can be performed. The intestinal lesion of CD can be patchy and four to six biopsies should be obtained at endoscopy. The patient must be on a gluten-containing diet at the time of biopsy but there is no consensus about how long or how much gluten must be provided before biopsy. Screening tests can remain positive for up to 18 months after starting a GFD. It is important to follow people who have positive tissue transglutaminase or endomysial antibody tests and normal biopsies who do not go on a GFD. If the titres of the screening tests increase, rebiopsy is recommended.

PA: What messages would you like to convey to Canadian gastroenterologists?

SC: $\mathrm{CD}$ is the most underdiagnosed common autoimmune disorder in North America. It can present at any age including in the elderly, as well as in obese patients and those with constipation. The wide variety and severity of symptoms 
frequently result in misdiagnoses of irritable bowel syndrome, chronic fatigue syndrome and/or fibromyalgia. In addition, there are significant delays in the diagnosis. Studies (15) from Columbia University (New York, USA) and the Canadian celiac health survey revealed average delays of 10 to 11 years after development of symptoms. Before diagnosis, $37 \%$ of the Canadian survey respondents consulted two or more family physicians about their symptoms, $27 \%$ consulted three or more physicians and $14 \%$ consulted two or more gastroenterologists.

\section{REFERENCES}

1. Fasano A, Berti I, Gerarduzzi I, et al. Prevalence of celiac disease in at-risk and not-at-risk groups in the United States: A large multicenter study. Arch Intern Med 2003;163:286-92.

2. Rampertab SD, Pooran N, Brar P, Singh P, Green PH. Trends in the presentation of celiac disease. Am J Med 2006;119:355.e9-14.

3. Green PH. The many faces of celiac disease: Clinical presentation of celiac disease in the adult population. Gastroenterology 2005;128(4 Suppl 1):S74-8.

4. Lo W, Sano K, Lebwohl B, Diamond B, Green PH. Changing presentation of adult celiac disease. Dig Dis Sci 2003;48:395-8.

5. Cranney A, Zarkadas M, Graham I, et al. The Canadian celiac health survey. Dig Dis Sci 2006. (in press)

6. Holm K, Maki M, Vuolteenaho N, et al. Oats in the treatment of childhood coeliac disease: A 2-year controlled trial and a long-term clinical follow-up study. Aliment Pharmacol Ther 2006;23:1463-72.

7. Hogberg L, Laurin P, Falth-Magnusson K, et al. Oats to children with newly diagnosed coeliac disease: A randomised double blind study. Gut 2004;53:649-54.

8. Peraaho M, Kaukinen K, Mustalahti K, et al. Effect of an oats-containing gluten-free diet on symptoms and quality of life in
Successful management of CD requires a team approach, including the person with CD and his/her family; a physician, dietitian and celiac support group; an individualized treatment plan; use of evidence-based current information and resources; and regular follow-up to monitor compliance, nutritional status and provide additional information and ongoing support (16). Good dietary compliance will reduce the risk of complications and associated health care costs, and improve the quality of life in patients with CD.

coeliac disease. A randomized study. Scand J Gastroenterol 2004;39:27-31.

9. Storsrud S, Olsson M, Arvidsson Lenner R, Nilsson LA, Nilsson O, Kilander A. Adult coeliac patients do tolerate large amounts of oats. Eur J Clin Nutr 2003;57:163-9.

10. Janatuinen EK, Kemppainen TA, Julkunen RKJ, et al. No harm from five year ingestion of oats in coeliac disease. Gut 2002;50:332-5.

11. Hoffenberg EJ, Haas J, Drescher A, et al. A trial of oats in children with newly diagnosed celiac disease. J Pediatr 2000;137:361-6.

12. Picarelli A, Di Tola M, Sabbatella L, et al. Immunologic evidence of no harmful effect of oats in celiac disease. Am J Clin Nutr 2001;74:137-40.

13. Ivarsson A, Hernell O, Stenlund H, Persson LA. Breast-feeding protects against celiac disease. Am J Clin Nutr 2002;75:914-21.

14. Ivarsson A, Persson LA, Nystrom L, et al. Epidemic of coeliac disease in Swedish children. Acta Paediatr 2000;89:165-71.

15. Green PHR, Stavropoulos SN, Panagi SG, et al. Characteristics of adult celiac disease in the USA: Results of a national survey. Am J Gastroenterol 2001;96:126-31.

16. Case S. The gluten-free diet: How to provide effective education and resources. Gastroenterology 2005;128(4 Suppl 1):S128-34. 


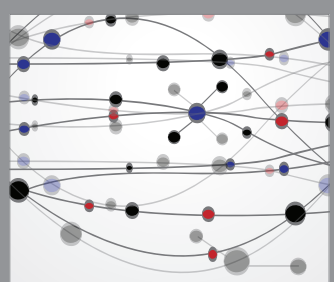

The Scientific World Journal
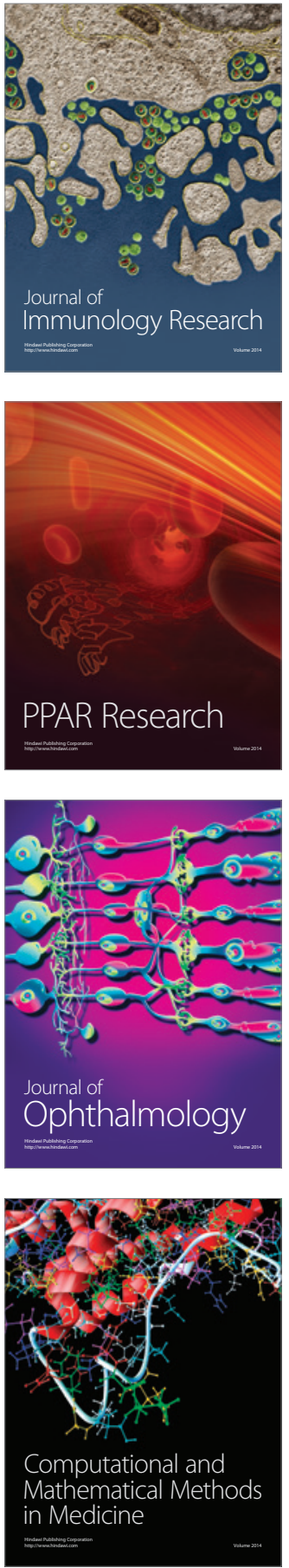

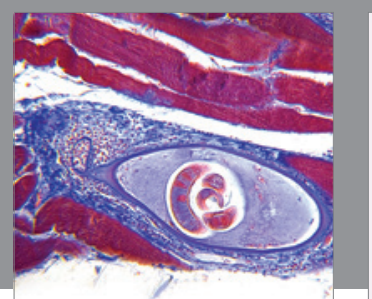

Gastroenterology Research and Practice

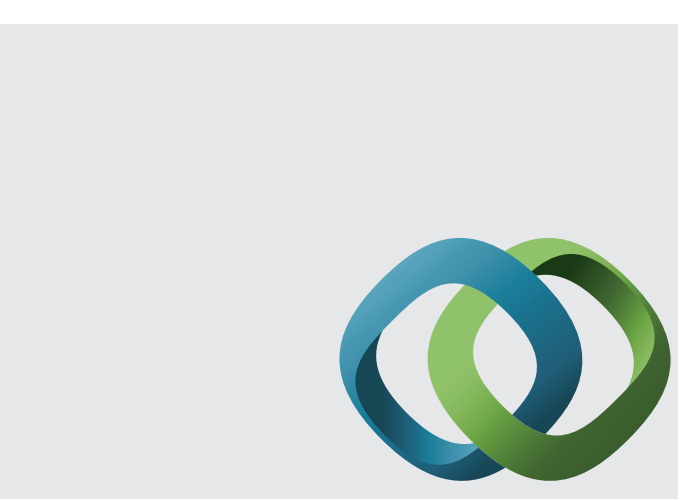

\section{Hindawi}

Submit your manuscripts at

http://www.hindawi.com
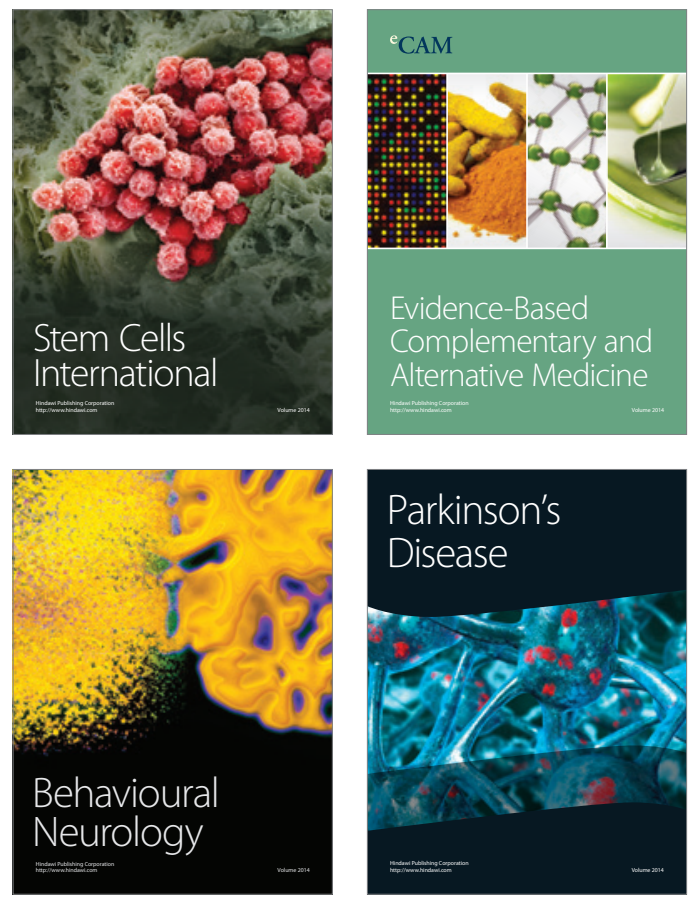
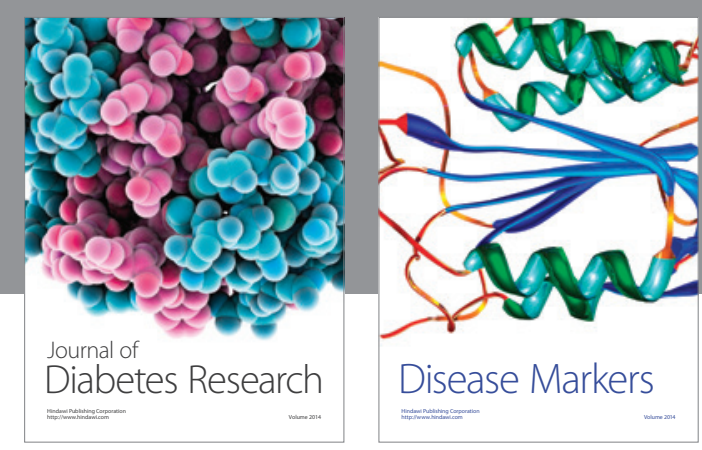

Disease Markers
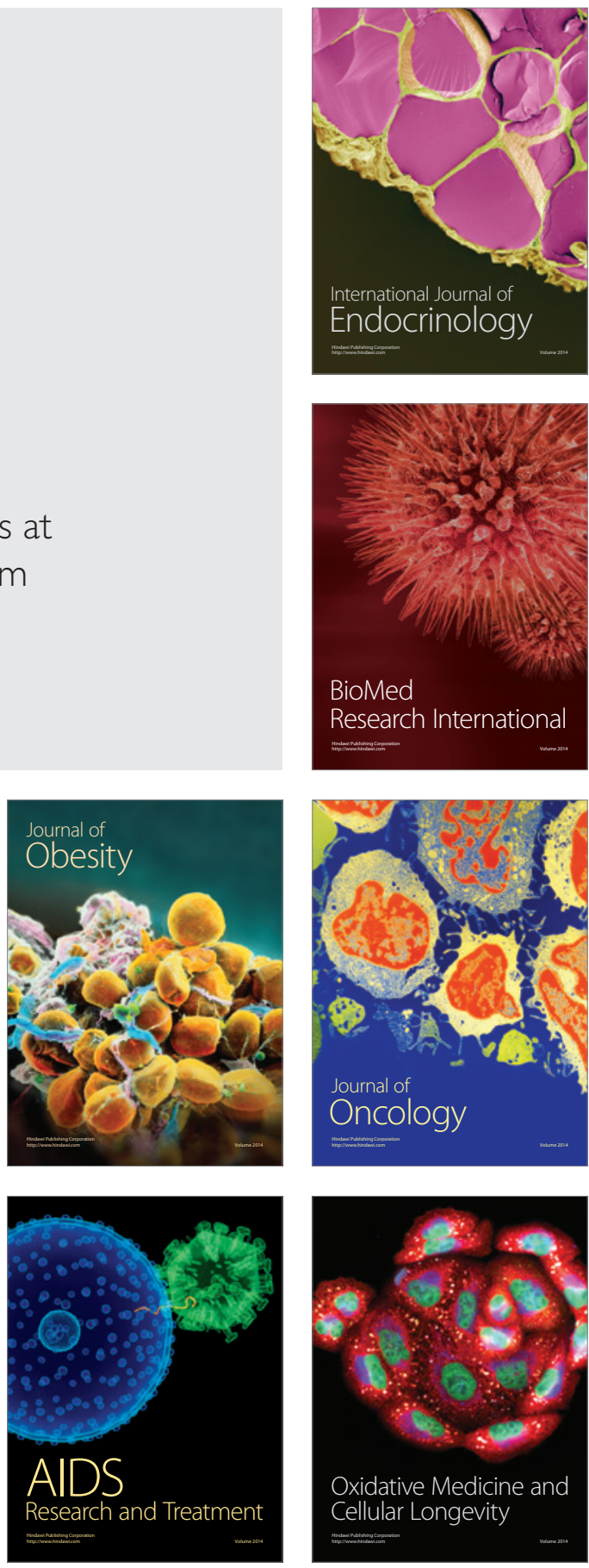